\title{
Human Cells, Tissues, and Cellular and Tissue-Based Products Distribution
}

National Cancer Institute

\section{Source}

National Cancer Institute. Human Cells, Tissues, and Cellular and Tissue-Based Products

Distribution. NCI Thesaurus. Code C133289.

Conveyance or shipment of Human Cells, Tissues, and Cellular and Tissue-Based

Products (HCT/Ps) that has met all release criteria. 